\title{
Duración y ritmo en la "nouvelle" de entreguerras
}

por Carmen Camero Pérez

El tiempo específico de la "nouvelle": una duración limitada, pero excepcional

La "nouvelle" del periodo de entreguerras se caracteriza por la corta y limitada duración de la historia narrada. La intención de los autores, que se separan ya netamente de esa "nouvelle-petit roman" de los siglos XVII y XVIII, así como de las largas "nouvelles" del siglo anterior, del tipo Carmen de Mérimée, es la de circunscribir la narración, marcando unos límites cronológicos precisos, que se anuncian ya, en algunos casos, en los títulos mismos. Así sucede, por ejemplo, en "Veillée" y "A l'aube" de Marcel Arland (in Les plus beaux de nos jours), "La belle journée" de Jacques de Lacretelle (in L'âme cachée),, "Une nuit de Shang-Haî" y. "Dimanche á SaintCloud" de Thomas Raucat (in Loin des blondes) o "La nuit de Noël" de Alexandre Arnoux (in Le cabaret). En todos estos casos, como bien puede deducirse, lo que se narra no es una "historia", entendida como conjunto de sucesos acaecidos a una persona, sino uno sólo de esos sucesos; en "Veillée" asistimos al velatorio de una difunta que tiene lugar durante una noche; "A l'aube" reduce aún más la duración a sólo unas horas, aquéllas que coinciden con el nacimiento del día; en "La belle journée", una pareja de ancianos, después de seis meses de soledad, vive un feliz día junto a su pequeño nieto; "Une nuit de Shang-Haî" y "Dimanche á Saint-Cloud", evocan ambas las horas pasadas por el personaje en busca de la mujer de sus sueños; "La nuti de Nočl" nos presenta a dos soldados que pasan la noche de Navidad en el frente, contándose mutuamente sus penas y aflicciones.

Aunque lo limitado de la duración no aparezca reflejado en el título, la lectura de la "nouvelle" revela "a posteriori" el carácter reducido de la cronología. En "La retraite de Russie" (in Le puits aux images) Marcel Aymé, con extraordinaria gracia y humor, nos narra la aventura de su joven personaje: "Petit-Doré", extremadamente listo y mucho más aventajado que sus compañeros de clase, cansado de soportar las desagradables bromas de su enemigo Léon Jars, que se empeña en hacerle creer que los pelirrojos no pueden orinar tan alto como los rubios y los morenos, decide un día vengarse de él, cuando en clase el profesor de historia le interroga acerca de "la retraite de Russie":

"-Il y avait le maréchal Ney. Au lieu de se sauver, il avait pris un fusil et c'était le plus brave. C'est pour ça que Napoléon l'a appelé le brave des braves. Le maréchal Ney s'était battu sous la Révolution. Il était né à Sarrelouis et il avait les cheveux roux ... 
Petit Doré se tourna vers la classe et répéta, d'une voix éclatante:

-Il avait les cheveux roux.

(...) et tourné vers le grand Jars, il jeta:

-Il avait les cheveux roux, et dans toute l'armée, il pissait plus haut que n'imprte lequel"1

Aymé, como vemos, no nos relata la vida del chico, ni siquiera una etapa de su existencia, sino unas horas, y de éstas, sólo privilegia unos momentos, aquellos en los que por fin Petit Doré puede vengarse de Léon Jars.

Del mismo modo podemos ver cómo Daniel-Rops en su "nouvelle" "L'eau malade" (in Les Oeuvres Libres) nos presenta a una joven que dialoga con su padrastro durante algunas horas, mientras esperan la llegada de la madre. "Testament" de Jean Schlumberger (in Les yeux de dix-huit ans) evoca los momentos finales de la vida de un anciano que, sintiendo próxima su muerte, decide dar a conocer a sus allegados su última voluntad. En "Le sermon difficile" de Louis Pergaud (in Les Rustiques), el narrador se limita a referir el sermón pronunciado un día por el cura del pueblo, que se creyó en la obligación de advertir a sus fieles adultos del peligro que sus hijos corrían, al entregarse a los juegos amorosos.

Para indicar la limitada duración de sus historias, los "nouvellistes" se encargan de poner de manifiesto el armazón cronológico de sus "nouvelles", permitiéndonos pues inscribir las acciones en un esquema temporal preciso. En "Prés de la côte 304"2, Ignace Legrand comienza la narración con la evocación de un ambiente, en la que vienen a mezclarse ciertas indicaciones relativas a la cronología:

"Enfin, un peu avanta le coucheur du soleil, les hommes avaient pu "monter" par un boyau.

(... On était enfin entré dans la tranchée

(...)" (p. 55)

El espacio referido nos remite claramente al campo de batalla; la historia comienza, como podemos comprobar, con la caída de la tarde; es entonces cuando, ya de vuelta en la trinchera, tras una penosa marcha que ha durado toda la jornada, el narrador y el protagonista inician su conversación a la que se unen otros soldados presentes. A través de ésta se pretende ofrecer el retrato de un hombre "le lietenant Mégevand" visto en un momento concreto y en una situación especial que ha influido y transformado su personalidad.

El final de la conversación, que marca también el final de la "nouvelle", coincide con la llegada de la noche, indicación cronológica que tanto el narrador como el personaje se encargan de señalar, circunscribiendo así la duración a unas pocas horas:

"La nuit était venue. Le ciel fourmillait d'étoiles" (p. 66)

“-Oh! qu'elle est belle! Ce ciel! Toutes ces étoiles (p. 67)

(1) Marcel Ayme, "La retraite de Russie", in Le puits aux imagens. Paris, Gallimard, 1932, p. 39.

(2) Ignace Legrand, "Prés de la côte 304", in Héry. Paris, Gallimard, 1936. 
Los acontecimientos narrados en "Le mur"3 de Sartre tienen lugar durante una noche; la acción comienza con la detención de Ibbieta y termina con el descubrimiento del escondite de Ramón Gris. Hacia las ocho de la tarde Ibbieta se entera de que ha sido condenado a muerte: "Vers huit heures du soir, un commandant entra avec deux phalangistes. Il avait une feuille de papier à la main. Il demanda au gardien:

-Comment s'appellent-ils, ces trois-lá?

-Steinbock, Ibbieta y Mirbal, dit le gardien

Le commandant mit ses lorgnons et regarda sa liste:

-Steinbock ... Steinbock ... Voilá. Vous êtes condamé à mort. Vous serez fusillé demain matin.

Il regarda encore:

-Les deux autres aussi, dit-il" (p. 15)

A partir de ese momento, Ibbieta empieza a vivir la angustiosa experiencia de saberse víctima de un pelotón de fusilamiento. Esto dura hasta el alba, momento en que sus dos compañeros son conducidos hasta el patio de la muerte; en esta ocasión es el mismo personaje el encargado de indicar el tiempo: "Voilá le jour" (p. 31). Una hora más tarde, Pablo Ibbicta es sacado de la celda para un nuevo interrogatorio: "Au bout d'une heure, on vint me chercher et no me conduisit au premier étage (...)" (p. 33).

Decidirá entonces contar una farsa a los falangistas, que terminará volviéndose contra él, ya que Ramón Gris es finalmente arrestado.

En "Le crimen d'une nuit", Emmanuel Bove nos hace asistir a la tragedia de Henri Duchemin, un ser pobre, solitario y desgraciado que se debate entre el suicidio y el crimen, como únicas soluciones para salir de su penoso estado. La duración, como ya bien indica el título, se reduce a una sola noche, pero el narrador se encargará también de especificar en su texto de qué noche se trata, localizando al mismo tiempo los acontecimientos. Al principio de la "nouvelle", se nos informa de que "C'était la veille de Noell" (p. 7); al final, utilizando idéntica construcción, se pone de manifiesto el tiempo transcurrido: "C'était le jour de Noěl" (p. 55)

Lacretelle, por su parte, en "La belle journée", no se limita a localizar temporalmente la acción al principio y al final de la "nouvelle", sino que se complace en recordarnos continuamente la duración de la historia por boca de sus personajes y por la suya propia:

"Une même expression d'espérance parut dans leurs yeux clignotants et fanés. Ils se tenaient toujours par la main et répétèrent doucement, presque en mêlant leur voix:

-Une belle journee!" (p. 165)

"Un long moment passa. D'un geste saccadé, elle reprit sa montre et regarda l'heure. Alors, d'une voix tranquille mais qui sonnait faux, el dit:

(3) Jean-Paul Sartre, "Le mur", in Le mur. Paris, Gallimard, 1972 (Primera ed. 1939).

(4) Emmanuel Bove, "Le crimen d'une nuit", in Henri Duchemin et ses ombres. Paris, Flammarion, 1983 (Primera ed. 1928, Emile Paul).

(5) Jacques de Lacretelle, "La belle joumée", in L'âme cachée. Paris, Gallimard, 1928. 
-Quelle belle journée!" (p. 169)

"Bien que le ciel fût moins bleu qu'á midi, c'était une belle journée" (p. 180)

Sin duda la función de estas repeticiones más que la de indicar la duración, es la de poner de relieve lo excepcional de la jornada en cuestión. si el "nouvelliste" evoca en su relato ese día es porque se trata "(d'une) belle journée". Para los protagonistas no es un día cualquiera, sino especial; el día en que, después de seis meses, van a volver a ver a su pequeño nieto. Las horas, momentos o instantes se cargan pues de valores sicológicos y afectivos, que muchos autores se encargan de subrayar en el interior de sus textos. Por citar sólo algunos, tomamos a título de ejemplo las "nouvelles" de M. Saint-Clair: Il y a quarante ans ${ }^{6}$, Colette: "Le cambrioleur" y Schlumberger: "Les yeux des dix-huit ans" ${ }^{\prime 8}$. En la primera, la narradora evoca los momentos de un pasado que vivió en compañía de su amante, momentos de plenitud y felicidad, momentos intensos que alcanzan para ella la calidad de esenciales:

“(...) histoire d'un court moment, d'un accord tel que sa résonance s'est prolongée tout au long d'une vie" (p. 9)

En el caso de Colette, un ladrón es sorprendido por la dueña de la casa, cuando se disponía a robar en su alcoba. Esta, vieja solterona, lo toma por un enamorado suyo; el protagonista se deja hacer por lo excepcional del acontecimiento:

"Une sorte de snobisme lui ôta l'envie d'insulter, de brutaliser, un snobisme qui respectait à la fois l'extravagante erreur de la vieille femme, et cet instant de sa propre vie qui imitait la vie d'un noble et romanesque héros ..." (p. 103)

Por último el protagonista de Schlumberger tendrá ocasión de experimentar en su propio cuerpo los efectos del alcohol; las horas vividas en ese estado le provocan emociones y vivencias intensas que nunca se habian producido antes y que tal vez no se reproducirán:

"Cette émotion d'un soir de fatigue et de vin sera peut-être dans ma vie la seule visitation d'un je ne sais quoi, auquel je suis bien empêché de donner un nom" (p. 120)

La "nouvelle" de entreguerras no necesita de largos períodos de tiempo; hemos podido ver cómo es suficiente una duración limitada a unos pocos días, horas e incluso momentos; pero al mismo tiempo se revela la singularidad de esos instantes, unidos como están a acontecimientos excepcionales y esenciales para los protagonistas. El tiempo aquí más que cronológico es un tiempo sicológico y lo importante es esa sustancia emocional del momento vivido, lo que sin duda explica el hecho de que los

(6) M. Saint-Clair, Il y a quarante ans. Paris, Gallimard, 1968 (Primera ed. 1936).

(7) Colette, "Le cambrioleur" in La femme cachée. Paris, Flammarion, 1981 (Primera ed. 1924).

(8) Jean Schlumberger, "Les yeux des dix-huit ans", in Les yeux des dix-huil ans. Paris, Gallimard, 1928. 
autores se interesen más por los estados de ánimo, sentimientos o sensaciones, que por los acontecimientos en sí.

\section{— El ritmo de la "nouvelle": un género apresurado}

El tiempo del relato no sólo es largo o corto, también puede resultar lento o rápido según el ritmo de la narracción. Este ritmo varía dependiendo del número más o menos grande de detalles ofrecidos por el narrador y de la extensión más o menos amplia de las secuencias descriptivas. Un narrador que se para poco en detalles y elimina o reduce al mínimo las descripciones, confiere a su relato un ritmo mucho más rápido que aquél que usa o abusa de tales procedimientos. La intención del "nouvelliste" es claramente la de ir directo al acontecimiento principal motivo de su narración, de ahí que el género se caracterice por la supresión de detalles accesorios que no estén ligados a la intriga misma de la "nouvelle". En este género nada es gratuito, y sin encontramos ciertos textos caracterizados por un discurso referencial, entendiendo éste como discurso que se centra en la descripción de objetos, hecho por otra parte poco frecuente, según hemos podido comprobar y verificar ${ }^{9}$, esto se explica por el hecho de que el objeto mismo es el centro de la narración y que por él y gracias a él los personajes se caracterizan y definen. En este tipo de "nouvelles", entre las cuales "L'Horloge" de Marcel Arland (in Les plus beaux de nos jours) merece ser citada como ejemplo significativo, existen abundantes detalles descriptivos, pero limitados y centrados en un sólo objeto: el reloj, símbolo para la anciana protagonista de su pasado feliz y que se carga pues de valores afectivos. Prueba evidente de la funcionalidad de estos objetos en la "nouvelle" es el hecho de que el narrador, a pesar de introducirnos desde el principio de la historia en el interior de la casa de la protagonista, no nos describe nada del ambiente o decorado a excepción del reloj.

Lo mismo sucede con las descripciones de la naturaleza, y es de nuevo Arland quien en su "nouvelle" "A l'aube" pone de manifiesto la ausencia de arbitrariedad del procedimiento en el género que nos ocupa. En este corto relato de diecinueve páginas, la mayor parte del texto está ocupada por la descripción de un valle a la hora del amanecer, pero es porque ese ambiente y decorado viene a explicar el estado anímico del personaje, al que captamos en un instante de su vida, instante que coincide con una agradable sensación de calma, paz y felicidad.

Estos "indices-informants", como los denomina Roland Barthes ${ }^{10}$, que nos informan en este caso acerca del lugar, están pues bien justificados en la "nouvelle", y advierten al lector de la funcionalidad de la descripción. Este, si está habituado a la lectura de relatos cortos, se dará cuenta, en efecto, rápidamente, de que el autor le está proponiendo un nuevo pacto, que la acumulación de detalles debe ser leída no como simple procedimiento tendente a crear los efectos necesarios para la representación ambiental, sino como información funcional constituida de la intriga misma.

(9) En nuestro estudio de la nouvelle francesa en el periodo de entreguerras (Tesis doctoral, leída en la Universidad de Sevilla el 22 de novicmbre de 1986) damos cuenta del bajo porcentaje de textos en los que aparece este tipo de discurso.

(10) Roland Barthes, "Introduction à l'analyse stucturale du récit", in Communications 8, 1966, pp. 1-27. 
En la inmensa mayoría de los casos, el "nouvelliste" adopta la actitud contraria, reduciendo al máximo descripciones y detalles, lo cual tiene una doble consecuencia; la primera está relacionada con el ritmo de la narración, que se vuelve rápido y acelerado; la segunda tiene que ver con el papel del lector, que al ver limitados los "indices -informants", se ve obligado a poner mucho de su parte en la imaginación o representación, tanto de los lugares como de los objetos y personajes. La "nouvelle" pues exige del lector una gran participación.

Tomando dos ejemplos de La femme cachée de Colette, el primero perteneciente a "La trouvaille" y el segundo a "L'assassin"11, podemos ver hasta qué punto el "nouvelliste" reduce las descripciones ambientales y de personajes. En "La trouvaille" sólo tres líneas bastan para describir el decorado de la acción: "(...) le salon ancien prolongé par une salle à manger rustique, les rideaux violet et argent, les tasses orange, le feu de bois" (p. 171). Colette se limita como podemos ver a informarnos de que el salón es antiguo y el comedor rústico; cada lector podrá a partir de ahí, y según su propia realidad, imaginar los lugares y cubrirlos con sus objetos. La "nouvelle" pues obliga a participar, pero respeta al mismo tiempo la libertad del lector, abriéndole una puerta a su propia imaginación.

En L'assassin", el relato comienza una vez que ya se ha cometido el crimen; nada se nos dice de los preliminares que precedieron al acontecimiento, sólo se nos informa del arma utilizada para tal fin:

"Quand il l'eût tuée, d'un coup de la petite masse de plomb sous laquelle elle maintenait ses papier d'emballage, Louis se trouva embarrassé. Elle gisait derriére le comptoir, une jambe pliée de travers, la tête retournée et le corps de face" (p. 116)

Conocemos en efecto cuál fue el arma del crimen, pero ni siquiera se nos dice dónde asestó el golpe el asesino a su víctima. Esta, por su parte, nos es descrita de forma sumamente esquemática; sabemos la posición de su cuerpo, de la cabeza y de una pierna, pero nada nos informa acerca de si había o no sangre o de la expresión de su rostro, por ejemplo.

Todas estas figuras de supresión, deben ser entendidas en la "nouvelle" como signos evidentes de que el centro de interés no se sitúa en esos aspectos del relato, que el autor trata de forma tan precipitada. Pues, en efecto, en "La trouvaille" el decorado es accesorio, lo importante y lo que verdaderamente constituye la narración es el estado anímico de la protagonista, una mujer divorciada, que en una tarde de domingo se da cuenta de que prefiere su estado anterior al actual, al tomar conciencia de su soledad. Del mismo modo en "L'assassin" no es el crimen lo que importa, sino la vida interior del protagonista y lo que éste siente y experimenta después de haber cometido la acción.

El interés del "nouvelliste" por atenerse sólo a lo esencial y a los momentos decisivos, explica el uso frecuente que éste hace de uno de los procedimientos narrativos que más aceleran el ritmo de la narración: la elipsis. Esta aparece en aquellas

(11) Coleue, "La trouvaille" y "L'assassin", in La femme cachée, op. cit. 
"nouvelles" cuya duración, a diferencia de la "nouvelle instant"l2, limitada a unas pocas horas, momentos o instantes, abarca un período más extenso de la vida del personaje, lo que no impide al autor profundizar sólo en ciertos acontecimientos. Con la elipsis, como indica Genette ${ }^{13}$, se suprime un tiempo de historia, cuya duración puede ser indicada o no; en el primer caso tenemos una elipsis explícita, mientras en el segundo la supresión deberá ser deducida por el lector de alguna laguna cronológica o solución de continuidad narrativa.

Los "nouvellistes" del período de entreguerras se sirven mayoritariamente del primer tipo, especificando claramente el período de tiempo transcurrido entre un acontecimiento y otro.

La "nouvelle" de Joseph Kessel "Les deux fous"14 se centra en un episodio tomado de entre otros muchos posibles de la vida del protagonista: un ingeniero burgués que tras la ocupación de Odesa por los rojos, teme por su vida y su libertad. El azar querrá que en su errar por las calles de la ciudad, encuentre a su amigo el doctor Anissine, director de un hospital siquiátrico y agente salvador, que se brinda a esconderlo en una de las habitaciones del centro. Allé permanecerá el protagonista durante todo un día y una noche junto con un loco peligroso. El acontecimiento evocado coincide pues con una de las más terribles experiencias de este hombre, que llega incluso a desear la muerte ante la desesperación y el terror que le produce el permanecer encerrado con el maníaco. La duración de esta historia es también, como podemos ver, muy corta. La secuencia siguiente nos presenta ya al personaje en Sebastopol, libre del terror rojo que lo acechaba; el paso de la anterior situación a ésta se realiza mediante una elipsis temporal:

"Des mois s'écoulèrent. Erchof déguisé en moujik avait pu gagner Sébastopol" (p. 141)

Lo que sucediera desde aquel día en que Erchof abandonó el siquiátrico hasta el momento en que ahora nos situamos poco importa, ya que lo que busca Kessel es un acontecimiento capital que tiene lugar en Sebastopol y que influye directamente en los hechos precedentes, sorprendiendo al personaje y a nosotros con él. Erchof encontrará en la citada ciudad a aquel loco peligroso que meses atrás destrozará sus nervios en el hospital de Odesa, pero ante su gran admiración descubrirá que el "fou furieux" no era sino otro Erchof intentando también salvar su vida: "Ils n'étaient fous ni l'un ni l'autre, mais á tous deux la cellule de l'asile avait sauvé la vie (p. 142).

En "Le cabinet chinois"15, Francis de Miomandre nos relata la historia de un anticuario de provincias que va a Paris con la intención de cobrar a un cliente unas deudas contraidas desde hacía tiempo. Lo que en principio iba a ser una corta estancia se prolonga hasta un período de seis meses, de entre los cuales el narrador privilegia sólo

(12) Tomamos el bien elegido término de "nouvelle-instant" de René Godenne. Ver La nouvelle française. Paris, P.U.F., 1974, pp. 124-125.

(13) Gérard Genette, Figures III, Paris, Seuil, 1972, p. 141.

(14) Joseph Kessel, "Les deux fous", in La steppe rouge. Paris, Gallimard, 1922.

(15) Francis de Miomandre, "Le cabinet chinois", in Le cabinet chinois. Paris, Gallimard, 1936. 
aquellos momentos que coinciden con los acontecimientos más significativos, eludiendo el resto: "Et les jours passérent, dans un vertige" (p. 239).

Por su parte Jean Cassou en "Les mauvais dimanches"16, nos relata la aventura amorosa de un joven alemana en París. Su amante es un hombre casado que vive en la provincia y cada domingo se traslada a la capital para ver a la chica. Aunque la duración de la historia abarca un período de varias semanas, queda de manifiesto la intención del autor de limitarse sólo a los tiempos fuertes de la acción, marcando el paso de domingo a domingo mediante una elipsis explícita: "Huit jours plus tard" (p. 77). Poco importa lo que suceda a cada uno de los personajes durante la semana, el centro de interés se sitúa en un solo día, en esos domingos que la joven vive su amores con el provinciano Lemarchand.

"La nuit de Portofino-Kulm" de Paul Morand ${ }^{17}$, como bien podemos deducir del título, privilegia de entre todos los acontecimientos y momentos evocados, aquél que tiene lugar una noche en la costa de Génova. Aunque la historia transcurre durante varios meses, sólo se profundiza en los momentos importantes que coinciden con los encuentros del narrador y el poeta gaélico O'Patah, de ahí el empleo de la elipsis: "Je revis O'Patah à Vénise trois mois plus tard" (p. 39).

Avanzando progresivamente en la duración de la historia narrada llegamos a la "nouvelle" de Franz Hellens "Esthella"18 en la que se evoca ya un amplio período de tiempo, que viene a cubrir varios años de la vida del personaje: desde el día de su boda con Esthella hasta la muerte de ésta años después. Se trata de una "nouvelle" de introspección sicológica, en la que el personaje, rememorando su pasado, se autoanaliza. Del tiempo transcurrido se van recordando y seleccionando ciertos acontecimientos, dejando de lado otros considerados secundarios, y para pasar de uno a otro, de nuevo la elipsis temporal se emplea como procedimiento preferido por el narrador: "Plusicurs mois se passèrent" (p. 215); "Les années passèrent" (p. 219), etc.

Comparando el tiempo de la narración, medido por el número de páginas de la "nouvelle": 15 , y consecuentemente por el tiempo de una lectura convencional, con el tiempo de la historia narrada ${ }^{19}$, esta "nouvelle" se presenta como un relato sumario ${ }^{20}$, ya que en pocas páginas se evoca todo un período de una vida.

Sumaria es también la "nouvelle" de Ignace Legrand: "Héry"21, en la que el personaje que tiene sesenta y cuatro años en la página $n^{9} 8$ : "Soixante quatre ans depuis l'automne dernier", se remonta al tiempo en que tenía cuarenta y tres para rememorar en las dieciséis páginas siguientes esos diez años de su vida pasada. El narrador se va encargando a lo largo del relato de marcar el paso del tiempo mediante repetidas anotaciones relativas a la edad del personaje:

"Il avait alors quarante-trois ans" (p. 24)

"Ainsi il attaignit sa cinquantième année" (p. 24)

(16) Jean Cassou, "Les mauvais dimanches", in De l' Etoile au Jardin des Plantes. Paris, Gallimard, 1935.

(17) Paul Morand, "La nuit de Portofino Kulm", in Fermé la nuit. Paris, Gallimard, 1973 (Primera ed. 1923).

(18) Franz Hellens, "Esthella", in Réalités fantastiques. Paris, Gallimard, 1931.

(19) Ver Paul Ricoeur, Temps et récit II. La configuration dans le récil de fiction. Paris, Seuil, 1984, p. 116.

(20) Ver G. Genette, op. cit., pp. 129-130.

(21) Ignace Legrand, "Héry", in Héry, op. cit. 
Como podemos observar, en una misma página se resume un período de vida de siete años.

En "Crimen passionnel"22 de Pierre Bost, la historia misma no es otra cosa que el relato de un juicio sumario, caracterizado como se sabe por su rápida tramitación. La "nouvelle" comienza con el juicio de Quérieux en el que el Juez da lectura al sumario evocando los distintos acontecimientos de la vida del acusado, desde que éste era niño hasta el momento del crimen, que coincide con su edad adulta.

La elipsis y el sumario vienen a caracterizar y definir el ritmo propio de la "nouvelle", ritmo rápido y acelerado que corre deprisa hacia su desenlace, que busca el acontecimiento esencial dejando de lado lo accesorio. Lo cuantitativo, como bien indica Paul Ricoeur ${ }^{23}$, también es cualitativo y nos permite, en este caso, calificar la "nouvelle" de entreguerras de género apresurado. Sin duda, la extensión aquí condiciona (o viene condicionada); el "nouvelliste" no dispone de muchas páginas, y por tanto de mucho tiempo, como para detenerse en detalladas descripciones.

(22) Pierre Bost, "Crime passionnel", in Un grand personnage. Paris, Gallimard, 1935.

(23) Ver P. Ricoeur, op. cit. pp. 117-118. 